\title{
Solution blow spun nanocomposites of poly(lactic acid)/cellulose nanocrystals from Eucalyptus kraft pulp
}

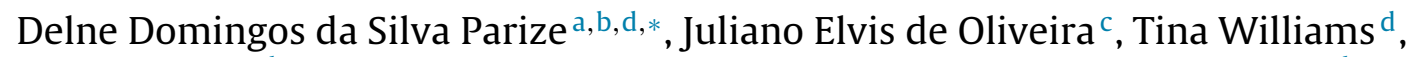 \\ Delilah Wood ${ }^{\mathrm{d}}$, Roberto de Jesús Avena-Bustillos ${ }^{\mathrm{e}}$, Artur Piotr Klamczynski ${ }^{\mathrm{d}}$, \\ Gregory Melvin Glenn ${ }^{\mathrm{d}}$, José Manoel Marconcini ${ }^{\mathrm{a}, \mathrm{b}}$, Luiz Henrique Capparelli Mattoso ${ }^{\mathrm{a}, \mathrm{b}}$ \\ a Postgraduate Program in Materials Science and Engineering (PPG-CEM), Federal University of São Carlos (UFSCar), Rodovia Washington Luis, km 235, CEP \\ 13565-905, São Carlos, SP, Brazil \\ ${ }^{\mathrm{b}}$ National Nanotechnology Laboratory for Agriculture (LNNA), Embrapa Instrumentation, Rua XV de Novembro, n. 1452, CEP 13560-970, São Carlos, SP, \\ Brazil \\ ${ }^{\mathrm{c}}$ Department of Engineering (DEG), Federal University of Lavras (UFLA), Avenida Doutor Sylvio Menicucci, n. 1001, CEP 37200-000, Lavras, MG, Brazil \\ d Bioproducts Research Unit (BRU), Western Regional Research Center (WRRC), Agricultural Research Service (ARS), United States Department of \\ Agriculture (USDA), 800 Buchanan Street, Albany, CA 94710, USA \\ e Healthy Processed Foods Research (HPFR), Western Regional Research Center(WRRC), Agricultural Research Service (ARS), United States Department of \\ Agriculture (USDA), 800 Buchanan Street, Albany, CA 94710, USA
}

\section{A R T I C L E I N F O}

\section{Article history:}

Received 28 January 2017

Received in revised form 3 July 2017

Accepted 7 July 2017

Available online 10 July 2017

\section{Keywords:}

Cellulose nanocrystals

Poly(lactic acid)

Maleic anhydride

Solution blow spinning

Nanocomposites

Nanofibers

\begin{abstract}
A B S T R A C T
Cellulose nanocrystals (CNCs) were extracted from Eucalyptus kraft pulp by sulfuric acid hydrolysis, and esterified with maleic anhydride $\left(\mathrm{CNC}_{\mathrm{MA}}\right)$. The incorporation of sulfate ester groups on the cellulose surface resulted in higher stability of the nanoparticles in aqueous suspensions and lower thermal stability. Then, PLA/CNC and PLA/CNC $\mathrm{CA}_{\mathrm{MA}}$ nanocomposites were successfully obtained by solution blow spinning (SBS) using dimethyl carbonate (DMC) as solvent. $\mathrm{CNC}$ and $\mathrm{CNC}_{\mathrm{MA}}$ indicated to be acting both as nucleating agents or growth inhibitors of PLA crystal and tends to favor the formation of PLA crystals of higher stability. A fraction of the nanocrystals indicate to be exposed on the surface of the PLA fibers, since the hydrophilicity of the composite films increased significantly. Such composites may have potential application as filtering membranes or adsorbents.
\end{abstract}

(C) 2017 Elsevier Ltd. All rights reserved.

\section{Introduction}

Cellulose nanocrystals (CNC) are highly crystalline nanoparticles and can be obtained from different sources of cellulose fibers and tunicate animals (Eichhorn et al., 2010). CNC have an acicular morphology (similar to a needle), with an average length ranging from $100 \mathrm{~nm}$ to a few micrometers and a diameter between

\footnotetext{
* Corresponding author at: Postgraduate Program in Materials Science and Engineering (PPG-CEM), Federal University of São Carlos (UFSCar), Rodovia Washington Luis, km 235, CEP 13565-905, São Carlos, SP, Brazil.

E-mail addresses: delne.ds@gmail.com,delne_ds@yahoo.com.br (D.D.d.S. Parize), juliano.materiais@gmail.com (J.E.d. Oliveira), tina.williams@ars.usda.gov (T.Williams),de.wood@ars.usda.gov (D. Wood), roberto.avena@ars.usda.gov (R.d.J. Avena-Bustillos), artur.klamczynski@ars.usda.gov (A.P. Klamczynski), greg.glenn@ars.usda.gov (G.M. Glenn), jose.marconcini@embrapa.br (J.M. Marconcini), luiz.mattoso@embrapa.br (L.H.C. Mattoso).
}

5 and $15 \mathrm{~nm}$ (Pérez \& Samain, 2010; Raquez et al., 2012). The $\mathrm{CNC}$ production is based on removing the amorphous regions of cellulose microfibrils, generated by imperfections at the interface of the crystalline domains. These imperfections turn cellulose microfibrils more susceptible to acid hydrolysis and more easily cleaved into smaller, crystalline fragments (Eichhorn, 2011). CNC can also be obtained by combining mechanical shear with enzymatic hydrolysis (Pa \& Ahola, 2007; Sun, Xu, Xu, \& Sun, 2013), although acid hydrolysis is the most widely used route for CNC production (Eichhorn et al., 2010; Figueirêdo et al., 2012).

CNC produced by hydrolysis with sulfuric acid have negatively charged ester sulfate groups on their surface, which facilitate their dispersion in most organic solvents. However, when hydrochloric acid is used for the hydrolysis, no functional groups or charges are formed on the surface of the CNC which results in more hydrogen bonding and greater agglomeration (Tian et al., 2016). Another difference is the reduced thermal stability of the CNC when using sulfuric acid versus hydrochloric acid hydrolysis (Teixeira 
et al., 2011; Teodoro et al., 2011). Several lignocellulosic sources of $\mathrm{CNC}$ have been studied, such as cotton (Satyamurthy, Jain, Balasubramanya, \& Vigneshwaran, 2011; Teixeira et al., 2010), sisal (Siqueira, Bras, \& Dufresne, 2009), bamboo (Chen et al., 2011), curaua (Corrêa, Teixeira, Pessan, \& Mattoso, 2010), coconut (Maheswari, Reddy, Muzenda, Guduri, \& Rajulu, 2012; Rosa et al., 2010) and Eucalyptus (Mesquita, Donnici, \& Pereira, 2010; Tonoli et al., 2012). Eucalyptus is an important source of lignocellulosic fibers that merits more extensive investigation for the production of nanocrystals and micro/nanofibrils (Tonoli et al., 2012).

Eucalyptus trees are grown extensively in Brazilian forest plantations because of their fast growth, high productivity, wide diversity of species and great adaptability (Stape et al., 2010). Productivity continues to increase in Brazil due to genetic improvements by cloning methods as well as the large availability of land and favorable climatic conditions (Mora \& Garcia, 2000). Eucalyptus wood is the dominant feedstock for the pulp and paper industry in Brazil, and worldwide. Bleached Eucalyptus pulp is the most abundant of the various pulps produced in Brazil. Eucalyptus pulp generally consists of shorter fibers with higher hemicellulose content than pine pulp. The higher levels of hemicelluloses facilitate defibrillation during mechanical treatment of pulp (Iwamoto, Abe, \& Yano, 2008). These characteristics favor the production of nanofibers and CNC from the Eucalyptus pulp (Tonoli et al., 2012).

CNC provide outstanding reinforcement in polymer nanocomposites as evidenced by the high mechanical strength and elastic modulus. In addition, they have surface groups, mainly hydroxyl groups, that can be functionalized if necessary to improve the interaction with the polymer matrix (Raquez et al., 2012). CNC also have environmental benefits, since they are obtained from renewable sources, do not have require high energy inputs during processing and are biodegradable (Clemons, 2010). Because of their hydrophilic nature, they are difficult to disperse in nonpolar solvents (Raquez, Habibi, Murariu, \& Dubois, 2013). One of the strategies to CNC dispersion is to use organic solvents to form a suspension and that can be blended with the desired polymer matrix (Eichhorn, 2011). Another strategy to improve dispersion is to chemically modify the $\mathrm{CNC}$ to improve the interaction at the polymer/CNC interface, improve the charge transfer, minimize the hydrophilicity of CNC and reduce moisture absorption (Gandini, 2008). The desired chemical modification depends on the application, since the incorporation of functional groups on the surface significantly modifies the way CNC interacts with the matrix material (Eichhorn, 2011).

Polymer nanofiber composites can be obtained by several methods, including solution blow spinning (SBS). The technique consists of feeding a polymer solution into a stream of pressurized air using a concentric nozzle. When the aerodynamic forces overcome the solution surface tension, a solution jet jettisons towards a collector. During the flight, the solvent is evaporated forming polymer fibers that are collected as non-woven mats (Medeiros, Glenn, Klamczynski, Orts, \& Mattoso, 2009; Parize, Foschini et al., 2016). The SBS is a promising technique for commercial scale nanofiber production, with lower cost compared to electrospinning. The SBS process is compatible with a wider variety of solvents than electrospinning and eliminates the need to use high voltages (Oliveira et al., 2011; Parize, Oliveira, Foschini, Marconcini, \& Mattoso, 2016). Another great advantage of SBS is that it is more portable as with commercial airbrush systems that facilitate depositing fibers on a broad range of collectors and surfaces (Behrens et al., 2014; Tutak et al., 2013). The applications for SBS mats include their use in sensors and biosensors, wound dressings, tissue sutures, drug delivery materials, filter membranes and adsorbents (Oliveira et al., 2011).

The production of poly(lactic acid) (PLA) nanocomposites reinforced with cellulose nanocrystals $(\mathrm{CNC})$ has been studied by electrospinning (Liu, Yuan, \& Bhattacharyya, 2012; Pirani,
Abushammala, \& Hashaikeh, 2013). Liu et al. (2012) studied the preparation of PLA/CNC electrospun composites and found an average fiber diameter of approximately $300 \mathrm{~nm}$ and that the $\mathrm{CNC}$ were not on the surface of the PLA fibers. In addition, the incorporation of CNC did not change the morphology of the fibers; however, the crystallization temperature was decreased, indicating that the CNC induced PLA nucleation, acting as heterogeneous nucleation sites. There are very few studies reporting the production of SBS nanocomposites. Oliveira, Grassi et al. (2013) showed that PLA nanocomposites reinforced with multi-walled carbon nanotubes (MWCNT) was effective in biosensors for the detection of hydrogen peroxide.

In this way, the aim of this study was to prepare PLA/CNC and $\mathrm{PLA} / \mathrm{CNC}_{\mathrm{MA}}$ nanocomposites using SBS, which was never studied before. The morphology, microstructure and thermal behavior of neat PLA and nanocomposite mats have also been investigated.

\section{Experimental}

\subsection{Materials}

Bleached Eucalytus kraft pulp was obtained from Suzano Pulp and Paper (Brazil). Sulfuric acid was obtained from Thermo Fisher Scientific, Sao Paulo, Brazil. Cellulose dialysis tubing, dimethyl carbonate (DMC) and maleic anhydride were purchased from Sigma-Aldrich, Sao Paulo, Brazil. Poly(lactic acid) (PLA) Ingeo ${ }^{\mathrm{TM}}$ 2003D $\left(\mathrm{M}_{\mathrm{w}} \approx 200,000 \mathrm{~g} \mathrm{~mol}^{-1}, 4 \mathrm{wt} \%\right.$ D-lactid acid isomer) was obtained from NatureWorks ${ }^{\circledR}$ LLC (Minnetonka, MN, USA).

\subsection{Extraction of cellulose nanocrystals (CNC)}

Cellulose nanocrystals (CNC) were extracted according to Tonoli et al. (Tonoli et al., 2012). First, $5 \mathrm{~g}$ of bleached Eucalyptus kraft pulp was added to $100 \mathrm{~mL}$ of sulfuric acid $\left(\mathrm{H}_{2} \mathrm{SO}_{4}, 60 \mathrm{wt} \%\right)$ and stirred vigorously for $60 \mathrm{~min}$ in a silicone oil bath at $45^{\circ} \mathrm{C}$. Cold deionized water $(500 \mathrm{~mL})$ was added to the suspension to stop the reaction. The resulting suspension was centrifuged ( 10 min at $4000 \mathrm{rpm}$ ). The acidic supernatant was discarded and the pellet was suspended in $500 \mathrm{~mL}$ of deionized water and dialyzed in a container of tap water with a constant flow of fresh water $(\sim 48 \mathrm{~h})$ until $\mathrm{pH} 6$ was approximated. The dialyzed suspension was sonicated for $3 \mathrm{~min}$ at $50 \%$ of amplitude (Sonifier ${ }^{\circledR} 450$, BRANSON), frozen and freezedried (FreeZone 4.51 Console, LABCONCO).

\subsection{CNC surface modification $\left(C_{N} C_{M A}\right)$}

CNC surface modification was performed by esterification with maleic anhydride (MA) in order to obtain unsaturations on the cellulose surface, based on Teodoro et al. (Teodoro et al., 2016). For that, $3.0 \mathrm{~g}$ of dried CNC (vacuum oven overnight at $60^{\circ} \mathrm{C}$ ) were added to $20 \mathrm{~g}$ of molten maleic anhydride $\left(60^{\circ} \mathrm{C}\right)$, which were sonicated for $10 \mathrm{~min}$ at $20 \%$ of amplitude (Sonifier ${ }^{\circledR} 450$, BRANSON). The mixture was centrifuged ( $2500 \mathrm{rpm}$ for $5 \mathrm{~min}$ ) with successive washings with warm deionized water $\left(60^{\circ} \mathrm{C}\right)$ until approximately $\mathrm{pH} 6$ was reached. Then, the mixture was frozen and freeze-dried (FreeZone 4.51 Console, LABCONCO).

\subsection{PLA/CNC and PLA/CNC $M A$ suspensions}

Polymer suspensions were prepared using freeze-dried cellulose nanocrystals ( $\mathrm{CNC}$ and $\mathrm{CNC}_{\mathrm{MA}}$ ), previously dried in a vacuum oven overnight at $60^{\circ} \mathrm{C}$ and sonicated in one of three concentrations $(0.1,1.0,3.0 \% \mathrm{w} / \mathrm{v})$ of DMC for $5 \mathrm{~min}$ at $70 \%$ of amplitude (Sonifier ${ }^{\circledR}$ 450 , BRANSON). The suspension was then transferred to a Falcon flask tube and PLA pellets were added $(8.0 \% \mathrm{w} / \mathrm{v}$, based on DMC 
volume), and stirred continuously at $50^{\circ} \mathrm{C}$ until complete PLA solubilization occurred $(\sim 2 \mathrm{~h})$. For polymer solutions, PLA pellets were directly added in DMC $(8.0 \% \mathrm{w} / \mathrm{v})$ in a Falcon flask tube under continuous stirring at $50^{\circ} \mathrm{C}$ until complete solubilization $(\sim 2 \mathrm{~h})$. After solubilization, the solutions/suspensions were transferred into a 10 mL glass syringe (B-D Yale, Becton-Dickinson \& Co., USA) which was placed in a syringe pump (SBS apparatus).

\subsection{Solution blow spinning (SBS)}

PLA/CNC and PLA/CNC ${ }_{\text {MA }}$ nanocomposites mats were obtained by solution blow spinning (SBS) different concentrations (0.1, $1.0,3.0 \%, \mathrm{w} / \mathrm{v}$ ) of polymer solution. The SBS apparatus consisted of a concentric nozzle configuration where a polymer solution/suspension was fed through the inner nozzle and pressurized air flowed through the outer nozzle. The inner nozzle was positioned so it protruded $2 \mathrm{~mm}$ beyond the concentric outer nozzle. The setting of SBS process parameters was made according to previous work (Parize, Foschini et al., 2016) (0.55 MPa of air pressure and a solution/suspension feed rate of $\left.50 \mu \mathrm{L} \mathrm{min}^{-1}\right)$. The feed rate was controlled with a syringe pump (KD Scientific, model 780101, Holliston, USA). The collector was kept fixed and positioned at a working distance of $40 \mathrm{~cm}$ from the nozzle. The SBS process was performed at ambient temperature $\left(21^{\circ} \mathrm{C}\right)$ and $35 \%$ relative humidity $(\mathrm{RH})$.

\subsection{Rheological properties}

Rheological properties of PLA/CNC and PLA/CNC $\mathrm{CAA}_{\mathrm{MA}}$ suspensions were determined using a rheometer (TA Instruments, model AR2000) with a concentric cylinder geometry. The measurements were performed at $25^{\circ} \mathrm{C}$ varying the shear rate from 1 to $100 \mathrm{~s}^{-1}$.

\subsection{Surface tension}

Surface tension of DMC, PLA solution, PLA/CNC and PLA/CNC $\mathrm{MA}_{\mathrm{MA}}$ suspensions was measured using a K100 Tensiometer (Krüss, Hamburg, Germany). The platinum plate was lowered into the polymer solution to determine its surface tension. The immersion depth of the plate was set at $2 \mathrm{~mm}$ and the measurements were done with a detection speed of $10 \mathrm{~mm} \mathrm{~min}^{-1}$ and sensitivity of $0.005 \mathrm{~g}$. For each sample, 50 measurements were made during $120 \mathrm{~s}$ and the surface tension values were expressed by the mean of the last 30 measurements.

\subsection{Scanning electron microscopy (SEM)}

SBS mats were coated with a thin layer of gold-palladium in a Denton Desk II Sputter Coating Unit (Denton Vacuum, Moorestown, $\mathrm{NJ}$ ). The morphology of these samples was analyzed on a scanning electron microscope Hitachi Field Emission S-4700 (Hitachi, Japan) operated at a voltage of $5 \mathrm{kV}$. Image s software (National Institutes of Health, USA) was used to measure the diameter of the nanofibers based on a minimum of 100 measurements.

\subsection{Transmission electron microscopy (TEM)}

Cellulose nanocrystals were imaged by transmission electron microscopy (TEM) to verify the nanostructure morphology. For this, a drop $(\sim 5 \mu \mathrm{L})$ of a dilute $\mathrm{CNC}$ aqueous solution was placed on a cooper grid (400 mesh, Ted Pella, No. 01822) and dried at room temperature. After $24 \mathrm{~h}$, the samples were stained with a contrast solution (uranyl acetate, $2 \% \mathrm{v} / \mathrm{v}$ ) by immersion of the grids for $2 \mathrm{~min}$. The analyzes were performed on a transmission electron microscope (FEI Tecnai 12, Hillsboro, OR). ImageJ software (National
Institutes of Health, USA) was used to determine the diameter and length of a minimum of 100 measurements.

\subsection{Fourier transform infrared spectroscopy (FTIR)}

FTIR spectroscopy were performed on a Thermo Scientific Nicolet IS10 equipment using attenuated total reflectance (ATR) accessory. Samples were previously overnight dried in a vacuum oven at $60^{\circ} \mathrm{C}$ before the analyzes. The measurements were collected in absorbance mode in the frequency range of $4000-650 \mathrm{~cm}^{-1}$ with a resolution of $4 \mathrm{~cm}^{-1}$. For each sample, 64 scans were performed.

\subsection{X-ray diffraction (XRD)}

XRD analysis was performed in a Philips X'Pert diffractometer. Scans were carried out from $5^{\circ}$ to $30^{\circ}(2 \theta)$ at a scan rate of $2^{\circ} \mathrm{min}^{-1}$ using $\mathrm{CuK}_{\alpha}$ radiation at $45 \mathrm{kV}$ and $40 \mathrm{~mA}$. The full width at halfmaximum height (FWHM) of the diffraction peaks was calculated by fitting the X-ray diffraction data with a Gaussian-Lorentzian function (Origin 7.5 software, Origin Lab, USA). The $d$-spacing for a given scattering angle $(2 \theta)$ was calculated by application of the Bragg equation (Eq. (1)), where $\lambda$ is the wavelength of the $\mathrm{CuK}_{\alpha}$ radiation $(\lambda=0.154 \mathrm{~nm})$.

$\boldsymbol{d}=\frac{\lambda}{2 \sin \boldsymbol{\theta}}$

The FWHM of the diffraction peak was calculated by fitting the $\mathrm{X}$-ray diffraction data with a Lorentzian function, and the crystallite size, $D$, was estimated by calculating the broadening of the diffraction peaks according to the Scherrer equation (Eq. (2)), where $k$ is the Scherrer constant that depends on the crystallite shape ( $k=0.94$ ) (Fernandes et al., 2011) and $\beta$ is the full width at halfmaximum height given in radians.

$D=\frac{\kappa \lambda}{\beta \cos \theta}$

\subsection{Thermogravimetric analysis (TGA)}

The thermal stability of Eucalyptus kraft pulp, $\mathrm{CNC}$ and $\mathrm{CNC}_{\mathrm{MA}}$ was measured in a Thermogravimetric Analyzer (TGA, PerkinElmer Pyris 1, Norwalk, CT). Before the running TGA tests, the samples were conditioned at $23^{\circ} \mathrm{C}$ for at least $48 \mathrm{~h}$ in a chamber with $50 \% \mathrm{RH}$ that was maintained with a saturated solution of calcium nitrate tetrahydrate $\left(\mathrm{Ca}\left(\mathrm{NO}_{3}\right)_{2} \cdot 4 \mathrm{H}_{2} \mathrm{O}\right)$ in deionized water. The samples ( $\sim 4 \mathrm{mg}$ ) were heated from 35 to $600^{\circ} \mathrm{C}$ at a rate of $10^{\circ} \mathrm{C} \mathrm{min}-1$ under nitrogen atmosphere at a flow rate of $20 \mathrm{~mL} \mathrm{~min}^{-1}$.

\subsection{Differential scanning calorimetry (DSC)}

Thermal properties of the SBS mats were analyzed using a Perkin Elmer DSC 8000 (Waltham, MA). The samples were conditioned in a chamber kept at $23^{\circ} \mathrm{C}$ and $50 \% \mathrm{RH}$ for at least $24 \mathrm{~h}$ before the test. The samples $(\sim 4 \mathrm{mg}$ ) were sealed in stainless steel pans and heated from 0 to $200^{\circ} \mathrm{C}$ at a rate of $5^{\circ} \mathrm{C} \mathrm{min}-1$. The DSC analysis was performed in triplicate. The degree of crystallinity $\left(\chi_{c}\right)$ of each sample was calculated using Eq. (3), where $\Delta H_{m}$ is the melting enthalpy of the sample, $\Delta H_{c c}$ is the cold crystallization enthalpy, and $\Delta H_{m}{ }^{0}$ is the melting enthalpy based on the assumption of $100 \%$ crystalline PLA (93.6 $\mathrm{Jg}^{-1}$ ) (Auras, Lim, Selke, \& Tsuji, 2010).

$\chi_{c}=\frac{\Delta H_{m}-\Delta H_{c c}}{\Delta H_{m}^{0}} \times 100$ 


\subsection{Zeta potential}

Potential charges on the surface of Eucalyptus kraft pulp, CNC and $\mathrm{CNC}_{\mathrm{MA}}$ were measured using aliquots of aqueous suspensions $(0.01 \% \mathrm{w} / \mathrm{v})$ in a Malvern 3000 Zetasizer NanoZS (Malvern Instruments, UK). Aqueous suspensions were previously sonicated for $5 \mathrm{~min}$ at $50 \%$ of amplitude (Sonifier ${ }^{\circledR} 450$, BRANSON). The measurements were made in triplicate at $25^{\circ} \mathrm{C}$.

\subsection{Energy dispersive spectroscopy (EDS)}

EDS analysis was performed in order to verify the chemical composition of the samples, especially sulfur from sulfate ester groups incorporated in the surface of the cellulose after extraction by acid hydrolysis. Samples of Eucalyptus kraft pulp, $\mathrm{CNC}$ and $\mathrm{CNC}_{\mathrm{MA}}$ were first coated with a carbon layer and the measurements were performed in an EDS Thermo Scientific (model 6742A) at $15 \mathrm{kV}$.

\subsection{Dynamic vapor sorption (DVS)}

DVS analysis was performed using a DVS-1 instrument (Surface Measurement Systems, Allentown, PA, USA) to obtain water vapor adsorption/desorption isotherms of the samples. Measurements were made on samples ( $\sim 5 \mathrm{mg}$ ) equilibrated to different $\mathrm{RH}$ first using a water vapor adsorption step (0-98\% RH) followed by a water vapor desorption step (98-0\% RH). The mass of the samples was monitored to obtain the isotherms. The measurements were performed at $25^{\circ} \mathrm{C}$ and the duration of each analysis was approximately $72 \mathrm{~h}$.

\section{Results and discussion}

Cellulose nanocrystals (CNC) were successfully extracted from Eucalyptus kraft pulp by sulfuric acid hydrolysis. Fig. 1 shows CNC micrographs obtained by transmission electron microscopy (TEM) at different magnifications revealed the characteristic acicular morphology (Klemm, Heublein, Fink, \& Bohn, 2005), indicating that the acid treatment was able to remove non-cellulosic constituents and expose the nanostructures. The $\mathrm{CNC}$ have a great tendency to agglomerate, due to their high surface area, making their dispersion in polymeric matrices challenging. The length $(\mathrm{L})$ of individual $\mathrm{CNC}$ ranged from 63 to $280 \mathrm{~nm}$ with an average value of $142 \pm 45 \mathrm{~nm}$. The diameters (D) ranged from 5 to $13 \mathrm{~nm}$, with an average value of $9 \pm 2 \mathrm{~nm}$. Thus, the calculated aspect ratio (L/D) was 16 . Similar results were obtained by Tonoli et al. (Tonoli et al., 2012) in which the average $\mathrm{L}$ and $\mathrm{D}$ of CNC prepared under the same conditions were $142 \pm 49 \mathrm{~nm}$ and $11 \mathrm{~nm} \pm 4$, respectively, with $\mathrm{L} / \mathrm{D} \sim 14$. Similar results were reported in other studies using different sources of cellulose, such as cotton with L/D 10 (Teixeira et al., 2010) and curaua with L/D 15 (Corrêa et al., 2010). On the other hand, different results were also found, such as CNC from sugarcane bagasse with L/D 64 (Teixeira et al., 2011), coconut with L/D 60 (Rosa et al., 2010) and sisal with L/D 43 (Siqueira et al., 2009). Therefore, different sources of cellulose generate different sizes of CNC.

After extraction, CNC surface modification was performed by esterification with maleic anhydride $\left(\mathrm{CNC}_{\mathrm{MA}}\right)$. X-ray diffractograms of Eucalyptus kraft pulp, $\mathrm{CNC}$ and $\mathrm{CNC}_{\mathrm{MA}}$ are shown in Fig. $1 \mathrm{~S}$ and the crystalline parameters are shown in Table 1 . Diffraction peaks were observed at $2 \theta$ angles of $16^{\circ}, 22^{\circ}$ and $35^{\circ}$, corresponding to crystallographic planes of (110), (200) and (004), respectively (Lu \& Hsieh, 2012). The degree of crystallinity for $\mathrm{CNC}$ and $\mathrm{CNC}_{\mathrm{MA}}$ were slightly greater than that of Eucalyptus kraft pulp. This result was expected since the pre-treatment of the cellulose pulp removed other components, such as lignin and extractives, the cellulose content and crystallinity degree of Eucalyptus kraft pulp is already high. Therefore, it was expected that the after acid hydrolysis the degree of
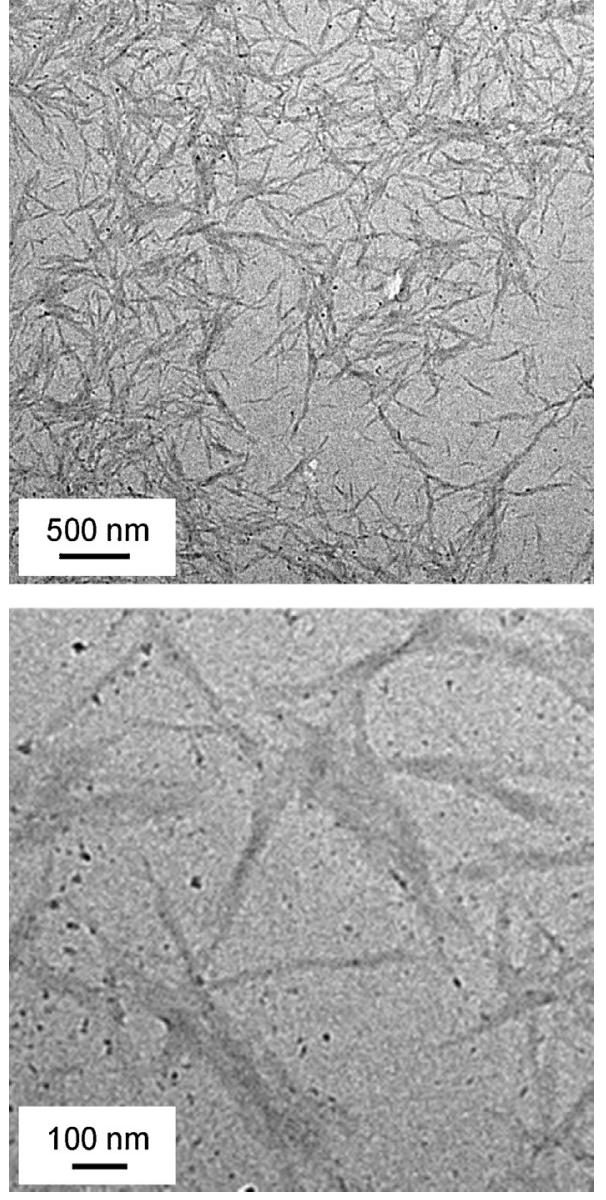

Fig. 1. TEM images of cellulose nanocrystals (CNC) extracted from Eucalyptus kraft pulp by sulfuric acid hydrolysis in different magnifications.

Table 1

Crystalline parameters of Eucalyptus kraft pulp, $\mathrm{CNC}$ e $\mathrm{CNC}_{\mathrm{MA}}$.

\begin{tabular}{lllll}
\hline Samples & $2 \theta\left(^{\circ}\right)$ & $d$-spacing $(\AA)$ & $D(\AA)$ & Crystallinity (\%) \\
\hline Eucalyptus kraft pulp & 15.8 & 6 & 19 & 61 \\
& 22.2 & 4 & 33 & \\
CNC & 15.7 & 6 & 22 & 64 \\
& 22.4 & 4 & 38 & \\
& 34.8 & 3 & 22 & \\
$\mathrm{CNC}_{\mathrm{MA}}$ & 15.6 & 6 & 22 & 63 \\
& 22.4 & 4 & 40 & \\
& 34.7 & 3 & 31 & \\
\hline
\end{tabular}

crystallinity would not change significantly. It was also observed that the $d$-spacing of crystallographic planes remained constant even after acid hydrolysis and surface modification with maleic anhydride, indicating that the crystal structure is unchanged. Crystallite sizes $(D)$ of $\mathrm{CNC}$ and $\mathrm{CNC}_{\mathrm{MA}}$ showed a higher value when compared to Eucalyptus kraft pulp, suggesting that part of the smaller crystallites were removed by acid hydrolysis.

FTIR spectroscopy was used to verify the occurrence of the chemical modification in the CNC with maleic anhydride of cellulose pulp, $\mathrm{CNC}$ and $\mathrm{CNC}_{\mathrm{MA}}$ (Fig. 2). All samples showed typical cellulose spectra, however in the $\mathrm{CNC}_{\mathrm{MA}}$ sample, a band was observed at approximately $1720 \mathrm{~cm}^{-1}$ which was attributed to the axial deformation of ester groups and carboxylic groups, indicating the CNC functionalization by maleic anhydride (Melo, Filho, Santana, \& Airoldi, 2009). The absence of bands between 1850 and $1780 \mathrm{~cm}^{-1}$ suggests the absence of free maleic anhydride, indicat- 


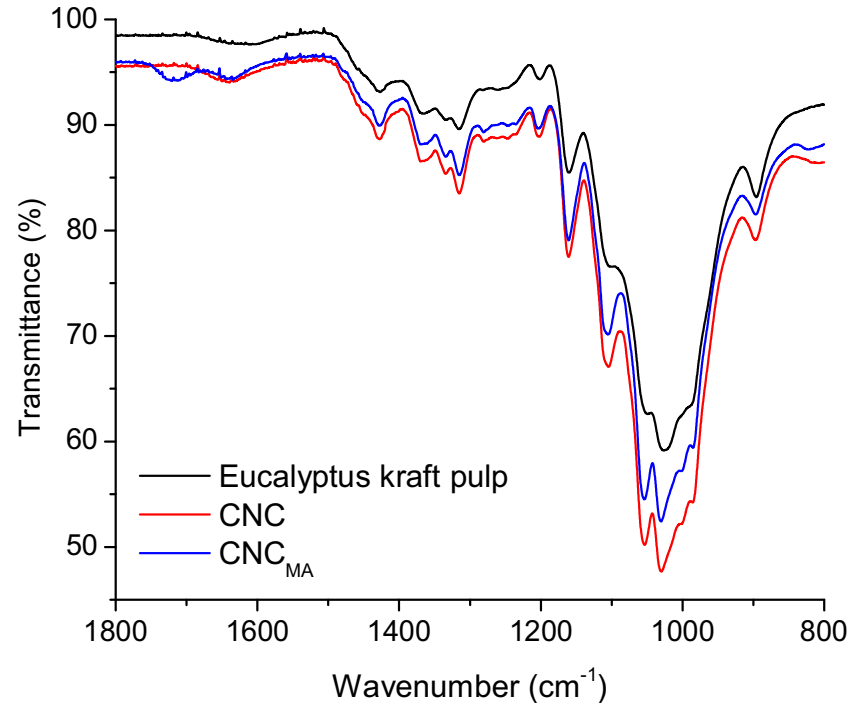

Fig. 2. FTIR spectra of Eucalyptus kraft pulp, $\mathrm{CNC}_{\mathrm{C}} \mathrm{CNC}_{\mathrm{MA}}$.

ing that the purification process was satisfactory (Liu, Sun, Qin et al., 2007; Liu, Sun, Zhang et al., 2007; Melo et al., 2009). The bands at 3327 and $2890 \mathrm{~cm}^{-1}$ were attributed to the axial deformation of $\mathrm{OH}$ groups and $\mathrm{C}-\mathrm{H}$ bonds, respectively. The band at $1634 \mathrm{~cm}^{-1}$ was attributed to the axial deformation of $\mathrm{C}-\mathrm{O}$ and $\mathrm{C}=\mathrm{C}$ bonds. The band at $1430 \mathrm{~cm}^{-1}$ was attributed to the symmetric angular deformation in the plane of $\mathrm{CH}_{2}$ group. The band at $1315 \mathrm{~cm}^{-1}$ was attributed to the symmetric angular deformation outside the plane of $\mathrm{CH}_{2}$ groups. The band at $1160 \mathrm{~cm}^{-1}$ was attributed to the angular deformation of $\mathrm{C}-\mathrm{O}$ bonds of esters. Bands in the region between 1052 and $1029 \mathrm{~cm}^{-1}$ were attributed to vibrations of $\mathrm{C}-\mathrm{O}$ bonds. The band at $893 \mathrm{~cm}^{-1}$ was attributed to the axial deformation of $\mathrm{C}-\mathrm{O}-\mathrm{C}$ bonds of $\beta$-glycosidic bonds present between the cellulose glucose units (Liu, Sun, Qin et al., 2007; Liu, Sun, Zhang et al., 2007; Melo et al., 2009; Silverstein \& Webster, 2000; Tian et al., 2016).

Energy dispersive spectroscopy (EDS) was performed on Eucalyptus kraft pulp, $\mathrm{CNC}$ and $\mathrm{CNC}_{\mathrm{MA}}$ samples, specifically to verify the presence of sulfur from the sulfate ester groups (Fig. 2S). The peak at $2.3 \mathrm{keV}$ was attributed to the presence of sulfur atoms. Eucalyptus kraft pulp showed the lowest sulfur peak intensity and the higher intensities were observed in $\mathrm{CNC}$ and $\mathrm{CNC}_{\mathrm{MA}}$ samples, indicating the incorporation of sulfate ester groups on the cellulose surface (Lu \& Hsieh, 2010; Sofla et al., 2016). $\mathrm{CNC}_{\mathrm{MA}}$ showed a slightly smaller peak compared to the CNC sample, indicating that part of the sulfate ester groups may have been replaced by groups from maleic anhydride esterification. Another evidence of surface modification was observed comparing the proportions of carbon $(0.27 \mathrm{keV})$ and oxygen $(0.52 \mathrm{keV})$ peaks. The intensity of oxygen peak was quite similar for all samples ( 430,000 a.u.). However, the intensity of the carbon peak was greatest for the $\mathrm{CNC}_{\mathrm{MA}}$ sample ( $\sim 870,000$ a.u.), followed by CNC sample ( 750,000 a.u.) and Eucalyptus kraft pulp ( $\sim 720,000$ a.u.). This difference indicates the presence of groups with higher carbon content in the $\mathrm{CNC}_{\mathrm{MA}}$ as is expected due to the maleic anhydride treatment.

Electrostatic charged particles, with positive or negative charges, tend to repel each other, preventing agglomeration and thus stabilizing the suspension. On the other hand, low electrostatic charged particles tend to agglomerate and precipitate, making their dispersion more challenging. Therefore, the stability of colloidal aqueous dispersions of Eucalyptus kraft pulp, $\mathrm{CNC}$ and $\mathrm{CNC}_{\mathrm{MA}}$ was measured by zeta potential, in which higher absolute values indicated greater stability of the aqueous suspension (Tian et al., 2016; Tonoli et al., 2012). Analyzing the results, the Eucalyptus kraft pulp showed the lowest zeta potential value module $(23.9 \mathrm{mV})$, as expected, followed by $\mathrm{CNC}(26.4 \mathrm{mV})$ and $\mathrm{CNC}_{\mathrm{MA}}(29.2 \mathrm{mV})$ samples. This can be explained by the incorporation of sulfate ester groups on the cellulose surface which are responsible for the stability of the suspensions (Teixeira et al., 2010).

The dynamic vapor sorption (DVS) measurements made on the Eucalyptus kraft pulp, $\mathrm{CNC}$ and $\mathrm{CNC}_{\mathrm{MA}}$ samples revealed their hygroscopic behavior (Fig. 3). Comparing the adsorption isotherms, Eucalyptus kraft pulp showed the highest weight change $(\Delta \mathrm{w})$ at $98 \%$ of relative humidity $(9.73 \%)$, indicating a higher amount of adsorbed water molecules. Analyzing the nature of the physical interaction between the adsorbent (sample) and the adsorbate (water), Eucalyptus kraft pulp had the highest amount of hydroxyls on the surface, favoring the formation of hydrogen bonding. CNC showed intermediate behavior (9.11\%) and $\mathrm{CNC}_{\mathrm{MA}}$ showed the lowest water adsorption values (8.02\%). These results can be explained by the incorporation of sulfate ester groups and groups from maleic anhydride, such as carbonyls and carboxylic acids, on the cellulose surface that led to a lower interaction with water molecules. The desorption isotherms revealed that all samples had affinity for water molecules, since the mass in the desorption isotherms was greater than the adsorption isotherms at a given $\mathrm{RH}$. This affinity was more evident when analyzing the hysteresis curves obtained by the difference in mass change of the adsorption and desorption cycles. These values were always positive. Mathematical modeling indicated that these isotherms can be better described by Freundlich model with very high correlation $\left(R^{2} \sim 0.999\right)$.

Thermodegradation of cellulose nanocrystals is a complex process, involving several parallel reactions, such as depolymerization, dehydration and decomposition of glycoside units. TG curves of $\mathrm{CNC}$ and $\mathrm{CNC}_{\mathrm{MA}}$ (Fig. 4, Table $1 \mathrm{~S}$ ) showed lower $\mathrm{T}_{\text {onset }}(245$ and $189^{\circ} \mathrm{C}$, respectively) when compared to Eucalyptus kraft pulp $\left(272^{\circ} \mathrm{C}\right)$. These results indicate that the groups in the cellulose surface from the acid hydrolysis and maleic anhydride esterification reduced the thermal stability of the cellulose. Alternatively, the increase of the nanocrystals surface area when compared to Eucalyptus kraft pulp could also reduce the $\mathrm{T}_{\text {onset }}$. According to Prins, Ptasinski, and Janssen (2006), the $\mathrm{T}_{\text {peak }}$ of hemicelluloses normally occurs in the range of $225-325^{\circ} \mathrm{C}$, residual lignin in the range of $250-500^{\circ} \mathrm{C}$ and cellulose in the range of $305-375^{\circ}$ Tonoli et al. (2012) reported the decomposition of the solid residues at around $440^{\circ} \mathrm{C}$. Eucalyptus kraft pulp showed two distinctive stages of weight loss ( $\mathrm{T}_{\text {peak }}$ at 314 and $430^{\circ} \mathrm{C}$ ). $\mathrm{CNC}$ showed a similar profile, showing three stages of weight loss $\left(\mathrm{T}_{\text {peak }}\right.$ at 270, 310 and $432^{\circ} \mathrm{C}$ ). Although the weight loss profile of the $\mathrm{CNC}$ was similar to the Eucalyptus kraft pulp, literature reports that sulfate groups incorporated in the cellulose surface generate a catalytic effect on the thermooxidative degradation of cellulose (Roman \& Winter, 2004). However, $\mathrm{CNC}_{\mathrm{MA}}$ presented a more complex thermodegradation profile and it was possible to observe four stages of weight loss ( $\mathrm{T}_{\text {peak }}$ at $235,313,424$ and $496^{\circ} \mathrm{C}$ ). These results indicate that the effect of surface modification with maleic anhydride was more dependent on the thermal stability of the cellulose than the incorporation of sulfate ester groups. The higher moisture content at $100{ }^{\circ} \mathrm{C}$ was observed on Eucalyptus kraft pulp due the presence of a higher amount of hydroxyl groups (Table $1 S$ ).

Composite films of PLA/CNC and PLA/CNC $\mathrm{MA}_{\mathrm{MA}}$ were produced by solution blow spinning (SBS) using the conditions previously determined to yield smaller diameter fibers (PLA concentration $=8 \% \mathrm{w} / \mathrm{v}$; air pressure $=0.55 \mathrm{MPa}$; feed rate $=50 \mu \mathrm{L} \mathrm{min}^{-1}$; concentration of $\mathrm{CNC}$ and $\mathrm{CNC}_{\mathrm{MA}}$ adjusted to $0.1,1.0$ and $3.0 \% \mathrm{w} / \mathrm{v}$ ) (Parize, Foschini et al., 2016). The rheological behavior of PLA solution and suspensions (Fig. 5) indicated that the addition of nanocrystals increased the viscosity and shear stress of the suspensions, wherein the highest values were obtained in the suspensions containing $3.0 \% \mathrm{w} / \mathrm{v}$ of nanocrystals. However, in a same concentration, no significant 
(a) Eucalyptus kraft pulp

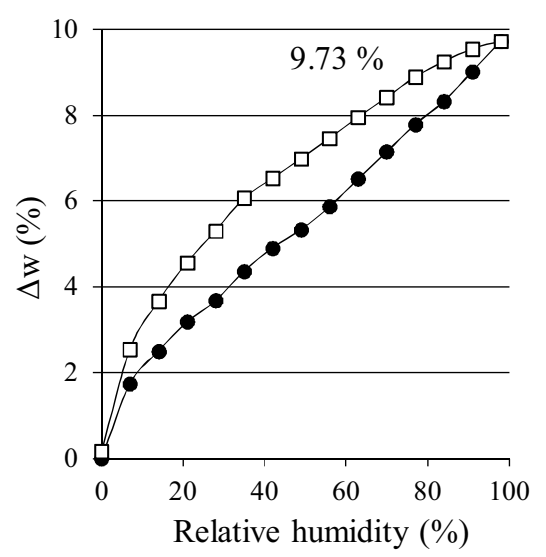

(c) $\mathrm{CNC}_{\mathrm{MA}}$

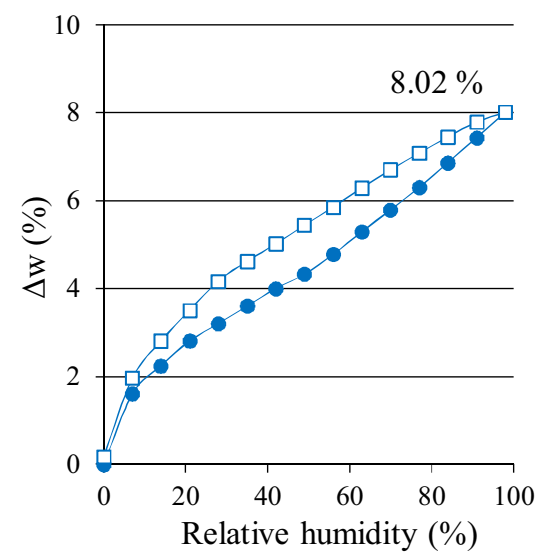

(b) $\mathrm{CNC}$

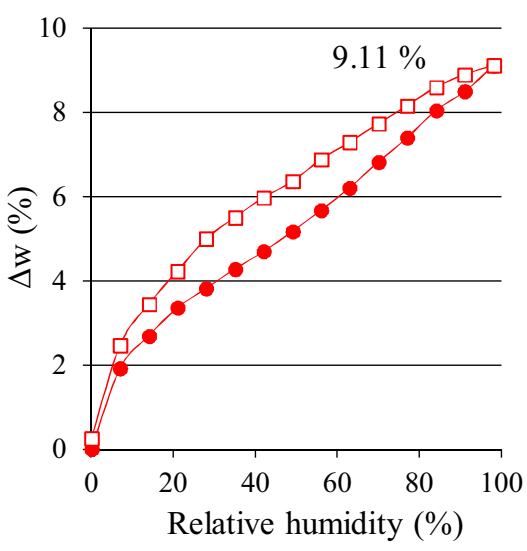

(d) Hysteresis

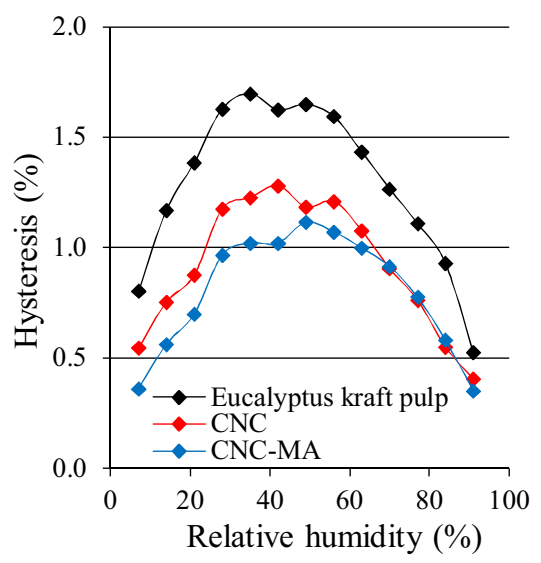

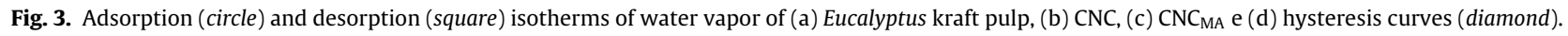

effect of nanocrystal viscosity was observed at a given shear rate. Most solutions showed typical Newtonian fluid behavior, however suspensions containing $3.0 \% \mathrm{w} / \mathrm{v}$ of nanocrystals showed a slight trend of pseudoplastic behavior at low shear rates. This trend suggests that the addition of $\mathrm{CNC}$ and $\mathrm{CNC}_{\mathrm{MA}}$ could modify the rheological behavior of PLA suspensions, due to the interaction of sulfate and maleic anhydride groups with PLA and/or the solvent.

Surface tension of PLA solution and suspensions containing CNC and $\mathrm{CNC}_{\mathrm{MA}}$ was measured and the results indicated no significant variations (PLA solution $28.9 \mathrm{mN} \mathrm{m}^{-1}$ and suspensions containing nanocrystals $28.7 \mathrm{mN} \mathrm{m}^{-1}$ ). Fiber diameter and bead formation tends to increase with the increase of surface tension of polymer solution (Huan et al., 2015; Jarusuwannapoom et al., 2005; Medeiros et al., 2009; Yu, Fridrikh, \& Rutledge, 2006). Yu et al. (2006) studied the formation of electrospun fibers and reported that the Rayleigh's instability in Newtonian fluids, which is influenced by the solution surface tension, is one of the reasons for the formation of beads and can be avoided by increasing the solution viscoelasticity. Comparing the electrospinning Taylor's cone with the solution cone formed in the solution blow spinning process (Oliveira, Moraes et al., 2013), the polymer solution jet is also subject to the Rayleigh's instability, which describes the interface instability between two fluids with different densities when the less dense fluid drives the denser fluid.

PLA films observed under SEM revealed a complex layered structure of fiber bundles with different diameters. In addition, some preferential orientation was observed in some cases (Fig. 6). The films with nanocrystals presented fibers with a slight roughness on the surface when compared to PLA films without nanocrystals. The roughness could be due changes in the rheological properties of the solutions caused by the presence of the nanocrystals and due the presence of the nanocrystals on the fiber surface. This increase on the fiber roughness suggests an increase in the surface area of the films, which may be favorable for adsorption applications, for example. It was not possible to verify the presence of the nanocrystals in the PLA fibers by SEM, but it is believed that the CNCs are present both internally of the fibers fully encapsulated by the PLA matrix, and in their surface.

The diameters of the fibers, as well the standard deviation, was measured (Fig. 3S) and there was no significant variation in the diameters of PLA fibers after incorporation of $\mathrm{CNC}$ and $\mathrm{CNC}_{\mathrm{MA}}$, although the films containing $\mathrm{CNC}_{\mathrm{MA}}$ showed a tendency towards smaller diameters as the concentration of nanocrystals increased. As previously reported, the viscosity of polymer solutions is one of the main factors affecting fiber diameter and higher viscosities tend to produce thicker fibers. Therefore, other factors may have influenced the PLA fibers formation, such as changes in the viscoelastic properties of the suspensions (Jarusuwannapoom et al., 2005).

A normal distribution of the fiber diameter was observed for the PLA, PLA/CNC and PLA/CNC $\mathrm{MA}_{\mathrm{MA}}$ films (Fig. 4S). Narrower and higher peak frequency distributions were observed, which means the smallest standard deviations, were obtained in the PLA films containing $3.0 \% \mathrm{w} / \mathrm{v}$ of $\mathrm{CNC}$ and $\mathrm{CNC}_{\mathrm{MA}}$. Films containing $1.0 \% \mathrm{w} / \mathrm{v}$ of nanocrystals and the PLA film without the addition of nanocrystals 
(a)

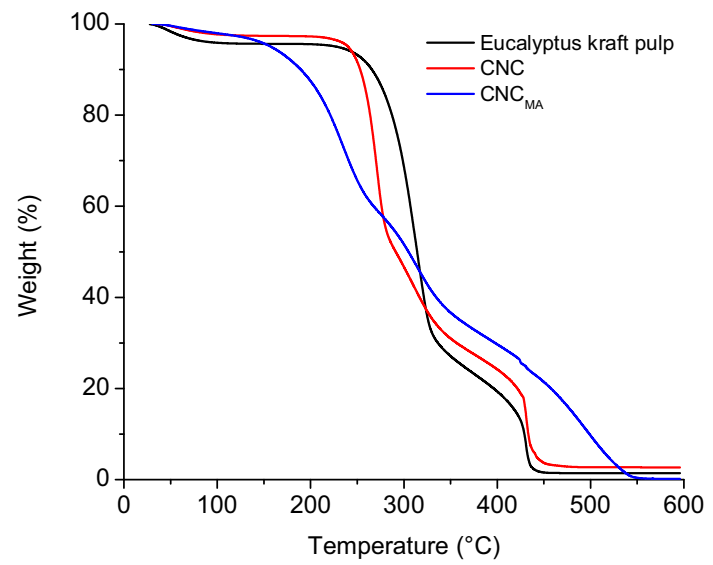

(b)

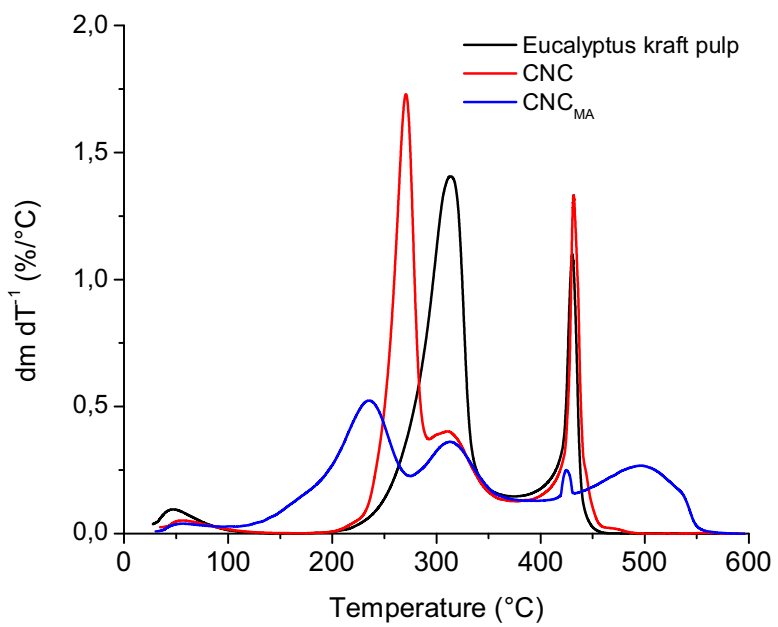

Fig. 4. TG (a) and DTG (b) curves of Eucalyptus kraft pulp, $\mathrm{CNC}$ e $\mathrm{CNC}_{\mathrm{MA}}$.
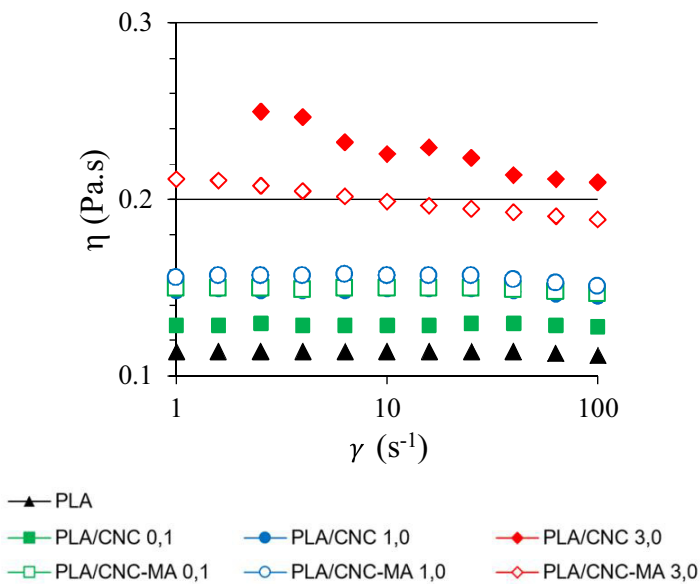

Fig. 5. Viscosity $(\eta)$ of PLA solution and suspensions containing 0.1 (square), 1.0 (circle) e 3.0 (diamond) \% w/v of $\mathrm{CNC} \mathrm{CNC}_{\mathrm{MA}}$ under different shear rates $(\dot{\gamma})\left(1-100 \mathrm{~s}^{-1}\right)$ at $25^{\circ} \mathrm{C}$.

showed broader peaks. The broader distributions with the lowest peak frequency were obtained in the films containing $0.1 \% \mathrm{w} / \mathrm{v}$ of nanocrystals. Thus, the results indicate the higher the concentration of nanocrystals, the smaller the standard deviation of the fiber diameter.
PLA
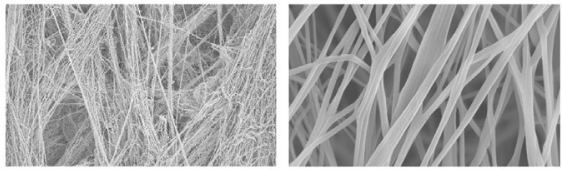

PLA/CNC $0.1 \% \mathrm{w} / \mathrm{v}$
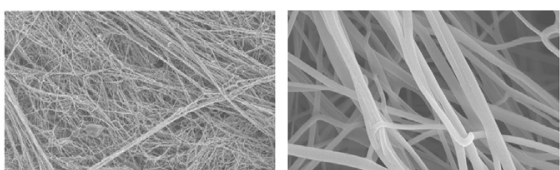

PLA/CNC $1.0 \% \mathrm{w} / \mathrm{v}$
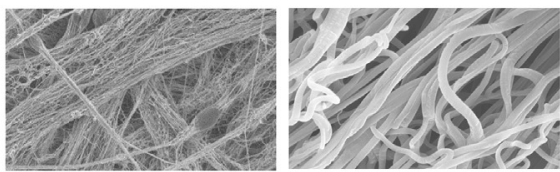

PLA/CNC $3.0 \% \mathrm{w} / \mathrm{v}$
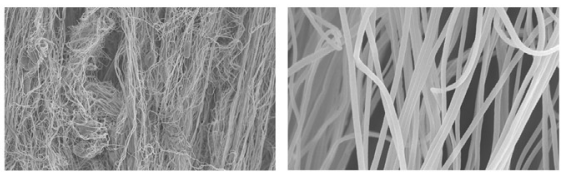

PLA/CNC $\mathrm{MA} 0.1 \% \mathrm{w} / \mathrm{v}$
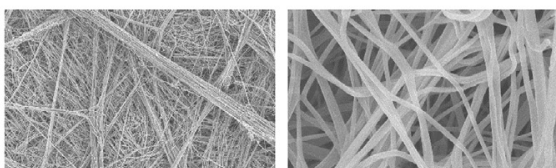

PLA/CNC $\mathrm{MA} 1.0 \% \mathrm{w} / \mathrm{v}$
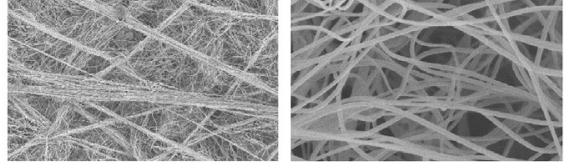

PLA/CNC $\mathrm{MA} 3.0 \% \mathrm{w} / \mathrm{v}$
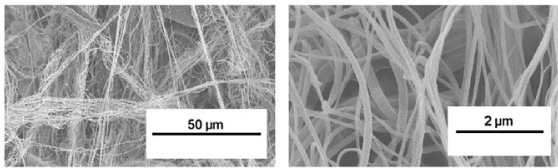

Fig. 6. SEM micrographs of PLA, PLA/CNC and PLA/CNC ${ }_{M A}$ nanocomposites obtained by solution blow spinning in different magnifications.

The water vapor adsorption and desorption isotherms of the samples of PLA, PLA/CNC $3.0 \% \mathrm{w} / \mathrm{v}$ and PLA/CNC $\mathrm{CA}_{\mathrm{MA}} 3.0 \% \mathrm{w} / \mathrm{v}$ films shown in Fig. 7 reveal that the PLA film without addition of the nanocrystals had the lowest weight change with the increase of the relative humidity $(0.83 \%)$. The film containing $3.0 \% \mathrm{w} / \mathrm{v}$ of CNC showed the highest weight change (2.69\%), followed by the film containing $3.0 \% \mathrm{w} / \mathrm{v} \mathrm{CNC}_{\mathrm{MA}}$ (2.21\%). Comparing the values at $98 \%$ of $\mathrm{RH}$, the film containing CNC showed a weight increase of approximately $220 \%$ and the film containing $\mathrm{CNC}_{\mathrm{MA}}$ an increase of about $160 \%$. These results corroborate the DVS data of the pure nanocrystals, in which the CNCs were more hydrophilic than the $\mathrm{CNC}_{\mathrm{MA}}$, transferring these hygroscopic characteristics to the composite films. These changes suggest that part of the nanocrystals are on the surface of the fibers, since if they were fully encapsulated by the PLA matrix, little or no change could be observed. Liu et al. (Liu et al., 2012) also reported that the nanocrystals were on the surface of the PLA fibers obtained by electrospinning. Observing the desorption isotherms, it was noticed that all samples had some affinity to water molecules, since the sample weight in desorption cycle was higher than the adsorption cycle. Analyzing the hysteresis curves, these differences are more evident, since the percentages were always positive.

The thermal properties of the PLA, PLA/CNC and PLA/CNC $\mathrm{MA}_{\mathrm{MA}}$ films were evaluated by differential scanning calorimetry (DSC) and no significant differences between the glass transition temperatures $\left(T_{g}\right)$ were observed with the addition of nanocrystals (Table 2). This indicates that the nanocrystals did not affect the 
(a) PLA

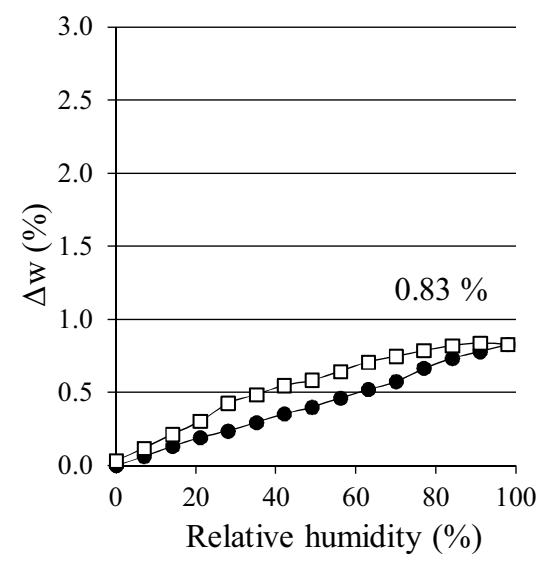

(c) $\mathrm{PLA} / \mathrm{CNC}_{\mathrm{MA}} 3.0 \% \mathrm{w} / \mathrm{v}$

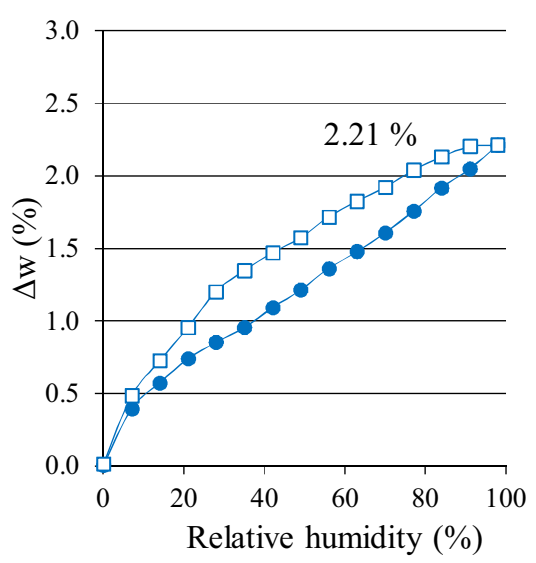

(b) PLA/CNC $3.0 \% \mathrm{w} / \mathrm{v}$

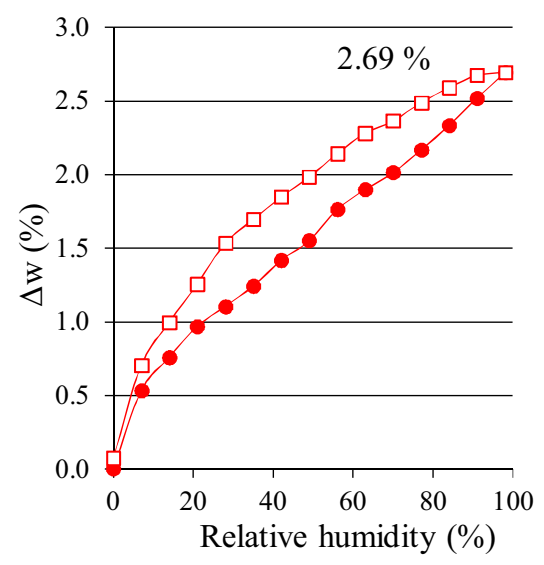

(d) Hysteresis

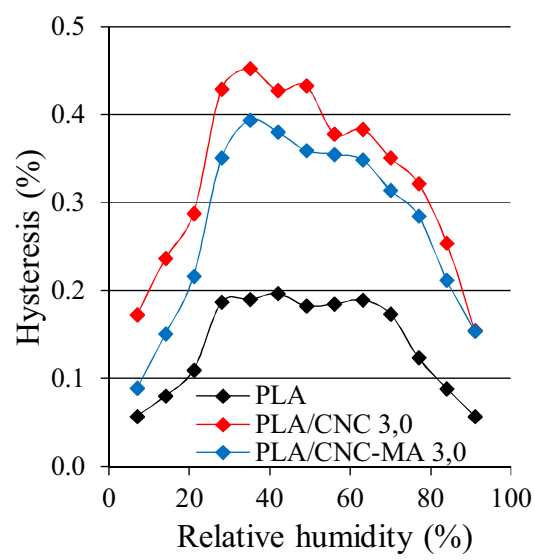

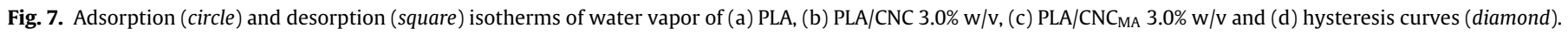

Table 2

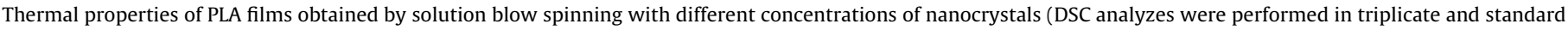
deviations less than 1 are not shown).

\begin{tabular}{|c|c|c|c|c|c|c|c|c|}
\hline PLA films (\% w/v of nanocrystal) & & $\mathrm{T}_{\mathrm{g}}\left({ }^{\circ} \mathrm{C}\right)$ & $\mathrm{T}_{\mathrm{cc}}\left({ }^{\circ} \mathrm{C}\right)$ & $\Delta \mathrm{H}_{\mathrm{cc}}\left(\mathrm{Jg}^{-1}\right)$ & $\mathrm{T}_{\mathrm{m} 1}\left({ }^{\circ} \mathrm{C}\right)$ & $\mathrm{T}_{\mathrm{m} 2}\left({ }^{\circ} \mathrm{C}\right)$ & $\Delta \mathrm{H}_{\mathrm{m}}\left(\mathrm{Jg}^{-1}\right)$ & $\chi_{\mathrm{c}}(\%)$ \\
\hline PLA & 0 & 56 & - & - & $156 \pm 6$ & $160 \pm 3$ & $25 \pm 3$ & $27 \pm 3$ \\
\hline $\mathrm{PLA} / \mathrm{CNC}$ & $\begin{array}{l}0.1 \\
1.0 \\
3.0\end{array}$ & $\begin{array}{l}55 \\
52 \pm 2 \\
54 \pm 1\end{array}$ & $\begin{array}{l}98 \pm 1 \\
98 \pm 1 \\
95\end{array}$ & $\begin{array}{l}4 \pm 1 \\
23 \pm 2 \\
3 \pm 1\end{array}$ & $\begin{array}{l}- \\
145 \pm 1 \\
-\end{array}$ & $\begin{array}{l}160 \\
156 \\
157\end{array}$ & $\begin{array}{l}25 \pm 3 \\
25 \pm 2 \\
21 \pm 2\end{array}$ & $\begin{array}{l}23 \pm 3 \\
2 \pm 1 \\
19 \pm 1\end{array}$ \\
\hline $\mathrm{PLA} / \mathrm{CNC}_{\mathrm{MA}}$ & $\begin{array}{l}0.1 \\
1.0 \\
3.0\end{array}$ & $\begin{array}{l}55 \pm 1 \\
54 \pm 1 \\
55\end{array}$ & $\begin{array}{l}99 \\
95 \pm 2 \\
95 \pm 2\end{array}$ & $\begin{array}{l}1 \\
3 \\
2 \pm 1\end{array}$ & $\begin{array}{l}151 \\
- \\
-\end{array}$ & $\begin{array}{l}160 \\
157 \\
156 \pm 1\end{array}$ & $\begin{array}{l}27 \\
23 \pm 3 \\
22 \pm 5\end{array}$ & $\begin{array}{l}28 \pm 2 \\
21 \pm 3 \\
21 \pm 4\end{array}$ \\
\hline
\end{tabular}

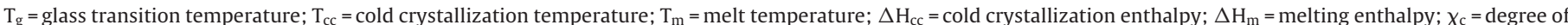
crystallinity.

translational and rotational movements of the PLA chains and the free volume of the amorphous regions, as also observed by Almasi et al. (Almasi, Ghanbarzadeh, Dehghannya, Entezami, \& Asl, 2015). All composite films showed exothermic peaks attributed to crystallization during the heating cycle, except by the pure PLA film. The cold crystallization temperatures $\left(\mathrm{T}_{\mathrm{cc}}\right)$ of films containing $3.0 \% \mathrm{w} / \mathrm{v}$ of $\mathrm{CNC}$ and 1.0 and $3.0 \% \mathrm{w} / \mathrm{v}$ of $\mathrm{CNC}_{\mathrm{MA}}$ tended to be lower compared to the films containing $0.1 \% \mathrm{w} / \mathrm{v}$ of nanocrystals. One explanation for this observation is that cellulose nanocrystals may be acting as growth inhibitors of PLA crystals during the fiber formation and solidification, thus reducing the crystallinity of the PLA in composite films. Two melting peaks $\left(\mathrm{T}_{\mathrm{m} 1}\right.$ and $\left.\mathrm{T}_{\mathrm{m} 2}\right)$ were observed in the pure PLA film, indicating the presence of two different crystal mor- phologies ( $\alpha^{\prime}$ and $\alpha$, respectively), wherein $\alpha^{\prime}$ crystals are a less organized structure with lower thermal stability when compared to $\alpha$ crystals. Except for films containing $1.0 \% \mathrm{w} / \mathrm{v}$ of CNC and $0.1 \%$ $\mathrm{w} / \mathrm{v}$ of $\mathrm{CNC}_{\mathrm{MA}}$, all composite films showed only one $\mathrm{T}_{\mathrm{m}}$, indicating the presence of only one crystal morphology $(\alpha)$. This can be attributed to the presence of the cellulose nanocrystals, which may be increasing the degree of orientation of the PLA chains and consequently forming more organized and stable PLA crystals (Almasi et al., 2015). The addition of $0.1 \% \mathrm{w} / \mathrm{v}$ of $\mathrm{CNC}$ and $\mathrm{CNC}_{\mathrm{MA}}$ did not significantly affect the PLA crystallinity $\left(\chi_{c}\right)$ compared to the neat PLA sample. The composite films containing 1.0 and $3.0 \% \mathrm{w} / \mathrm{v}$ of $\mathrm{CNC}$ and $\mathrm{CNC}_{\mathrm{MA}}$ showed lower PLA crystallinity. 


\section{Conclusions}

Cellulose nanocrystals (CNC) from Eucalyptus kraft pulp were successfully prepared by removing non-cellulosic constituents by sulfuric acid hydrolysis. Such hydrolysis also resulted the incorporation of sulfate ester groups on the cellulose surface, which made them more stable in aqueous suspensions. The methodology used for chemical modification of the CNC with maleic anhydride $\left(\mathrm{CNC}_{\mathrm{MA}}\right)$ was satisfactory, since differences in zeta potential were observed. $\mathrm{CNC}$ and $\mathrm{CNC}_{\mathrm{MA}}$ had lower thermal stability than Eucalyptus kraft pulp probably because of the sulfur component in functional groups on the cellulose surface act as catalysts in the thermo-oxidative degradation process. Addition of CNC increased the viscosity of the PLA suspensions in dimethyl carbonate (DMC) in the shear rate range studied. The increase in hydrophilicity of the composite films was greater that in the pure PLA samples probably because a fraction of the nanocrystals remained exposed on the surface of the fibers. Such composite films may have potential application in filtering membranes or adsorbents and the type of CNC modification can be changed according to the nature of the product to be removed. DSC analysis indicated that cellulose nanocrystals could be acting both as nucleating points and as inhibitors of growth of PLA crystals, since crystallization occurred only in the composite films. The addition of CNC tends to favor the formation of PLA crystals of higher stability, possibly due to the increase in the degree of polymer chain orientation.

\section{Acknowledgments}

The authors thank NatureWorks ${ }^{\circledR}$ for the donation of PLA samples, Suzano Pulp and Paper (Brazil) for the donation of bleached Eucalyptus kraft pulp and WRRC/ARS/USDA, CAPES, CNPq [Science without Borders Proc. 202445/2014-3; MCTI/SISNANO Proc. 402287/2013-4; Proc. 303796/2014-6] and Embrapa Rede Agronano for the financial support.

\section{Appendix A. Supplementary data}

Supplementary data associated with this article can be found, in the online version, at http://dx.doi.org/10.1016/j.carbpol.2017.07. 019.

\section{References}

Almasi, H., Ghanbarzadeh, B., Dehghannya, J., Entezami, A. A., \& Asl, A. K. (2015). Novel nanocomposites based on fatty acid modified cellulose nanofibers/poly(lactic acid): Morphological and physical properties. Food Packaging and Shelf Life, 5, 21-31. http://dx.doi.org/10.1016/j.fpsl.2015.04.003

Auras, R., Lim, L., Selke, S. E. M., \& Tsuji, H. (2010). Poly (lactic acid): Synthesis, structures, properties, processing and application. Hoboken: John Wiley \& Sons, Inc.

Behrens, A. M., Casey, B. J., Sikorski, M. J., Wu, K. L., Tutak, W., Sandler, A. D., \& Kofinas, P. (2014). In situ deposition of PLGA nanofibers via solution blow spinning. ACS Macro Letters, 3(3), 249-254. http://dx.doi.org/10.1021/ mz500049x

Chen, W., Yu, H., Liu, Y., Hai, Y., Zhang, M., \& Chen, P. (2011). Isolation and characterization of cellulose nanofibers from four plant cellulose fibers using a chemical-ultrasonic process. Cellulose, 18(2), 433-442. http://dx.doi.org/10. 1007/s10570-011-9497-z

Clemons, C. M. (2010). Wood flour. In M. Xanthos (Ed.), Functional fillers for plastics (2nd ed., pp. 213-223). Weinheim: WILEY-VCH Verlag GmbH \& Co. http://dx. doi.org/10.1017/CBO9781107415324.004

Corrêa, A. C., de Teixeira, E. M., Pessan, L. A., \& Mattoso, L. H. C. (2010). Cellulose nanofibers from curaua fibers. Cellulose, 17(6), 1183-1192. http://dx.doi.org 10.1007/s10570-010-9453-3

Eichhorn, S. J., Dufresne, A., Aranguren, M., Marcovich, N. E., Capadona, J. R., Rowan, S. J., ... \& Peijs, T. (2010). Review: Current international research into cellulose nanofibres and nanocomposites. Journal of Materials Science, 45(1), 1-33. http://dx.doi.org/10.1007/s10853-009-3874-0

Eichhorn, S. J. (2011). Cellulose nanowhiskers: Promising materials for advanced applications. Soft Matter, 7(2), 303. http://dx.doi.org/10.1039/c0sm00142b
Fernandes, A. N., Thomas, L. H., Altaner, C. M., Callow, P., Forsyth, V. T., Apperley, D. C., ... \& Jarvis, M. C. (2011). Nanostructure of cellulose microfibrils in spruce wood. Proceedings of the National Academy of Sciences of the United States of America, 108(47), 1195-1203. http://dx.doi.org/10.1073/pnas.1108942108

de Figueirêdo, M. C. B., de Rosa, M. F., Ugaya, C. M. L., Filho de, M. D. S. M. S., Braid da, A. C. C. S., \& de Melo, L. F. L. (2012). Life cycle assessment of cellulose nanowhiskers. Journal of Cleaner Production, 35, 130-139. http://dx.doi.org/10. 1016/j.jclepro.2012.05.033

Gandini, A. (2008). Polymers from renewable resources: A challenge for the future of macromolecular materials. Macromolecules, 41(24), 9491-9504. http://dx. doi.org/10.1021/ma801735u

Huan, S., Liu, G., Han, G., Cheng, W., Fu, Z., Wu, Q., \& Wang, Q. (2015). Effect of experimental parameters on morphological, mechanical and hydrophobic properties of electrospun polystyrene fibers. Materials, 8(5), 2718-2734. http://dx.doi.org/10.3390/ma8052718

Iwamoto, S., Abe, K., \& Yano, H. (2008). The effect of hemicelluloses on wood pulp nanofibrillation and nanofiber network characteristics. Biomacromolecules, 9(3), 1022-1026. http://dx.doi.org/10.1021/bm701157n

Jarusuwannapoom, T., Hongrojjanawiwat, W., Jitjaicham, S., Wannatong, L., Nithitanakul, M., Pattamaprom, C., .. . \& Supaphol, P. (2005). Effect of solvents on electro-spinnability of polystyrene solutions and morphological appearance of resulting electrospun polystyrene fibers. European Polymer Journal, 41(3), 409-421. http://dx.doi.org/10.1016/j.eurpolymj.2004.10.010

Klemm, D., Heublein, B., Fink, H. P., \& Bohn, A. (2005). Cellulose: Fascinating biopolymer and sustainable raw material. Angewandte Chemie - International Edition, 44(22), 3358-3393. http://dx.doi.org/10.1002/anie.200460587

Liu, D., Yuan, X., \& Bhattacharyya, D. (2012). The effects of cellulose nanowhiskers on electrospun poly (lactic acid) nanofibres. Journal of Materials Science, 47(7), 3159-3165. http://dx.doi.org/10.1007/s10853-011-6150-z

Liu, C. F., Sun, R. C., Qin, M. H., Zhang, A. P., Ren, J. L., Xu, F., . . \& Wu, S. B. (2007). Chemical modification of ultrasound-pretreated sugarcane bagasse with maleic anhydride. Industrial Crops and Products, 26(2), 212-219. http://dx.doi org/10.1016/j.indcrop.2007.03.007

Liu, C. F., Sun, R. C., Zhang, A. P., Ren, J. L., Wang, X. A., Qin, M. H., . . \& Luo, W. (2007). Homogeneous modification of sugarcane bagasse cellulose with succinic anhydride using a ionic liquid as reaction medium. Carbohydrate Research, 342(7), 919-926. http://dx.doi.org/10.1016/j.carres.2007.02.006

Lu, P., \& Hsieh, Y.-L. (2010). Preparation and properties of cellulose nanocrystals: Rods, spheres, and network. Carbohydrate Polymers, 82(2), 329-336. http://dx. doi.org/10.1016/j.carbpol.2010.04.073

Lu, P., \& Hsieh, Y. L. (2012). Cellulose isolation and core-shell nanostructures of cellulose nanocrystals from chardonnay grape skins. Carbohydrate Polymers, 87(4), 2546-2553. http://dx.doi.org/10.1016/j.carbpol.2011.11.023

Maheswari, C. U., Reddy, K. O., Muzenda, E., Guduri, B. R., \& Rajulu, A. V. (2012). Extraction and characterization of cellulose microfibrils from agricultural residue - Cocos nucifera L. Biomass and Bioenergy, 46, 555-563. http://dx.doi. org/10.1016/j.biombioe.2012.06.039

Medeiros, E. S., Glenn, G. M., Klamczynski, A. P., Orts, W. J., \& Mattoso, L. H. C. (2009). Solution blow spinning: A new method to produce micro- and nanofibers from polymer solutions. Journal of Applied Polymer Science, 113 2322-2330. http://dx.doi.org/10.1002/app30275

de Melo, J. C. P., Filho, da Filho, E. C. S., Santana, S. A. A., \& Airoldi, C. (2009). Maleic anhydride incorporated onto cellulose and thermodynamics of cation-exchange process at the solid/liquid interface. Colloids and Surfaces A: Physicochemical and Engineering Aspects, 346, 138-145. http://dx.doi.org/10. 1016/j.colsurfa.2009.06.006

de Mesquita, J. P., Donnici, C. L., \& Pereira, F. V. (2010). Biobased nanocomposites from layer-by-layer assembly of cellulose nanowhiskers with chitosan. Biomacromolecules, 11(2), 473-480. http://dx.doi.org/10.1021/bm9011985

Mora, A. L., \& Garcia, C. H. (2000). A cultura do eucalipto no Brasil. São Paulo: Sociedade Brasileira de Silvicultura.

Oliveira, J. E., Moraes, E. A., Costa, R. G. F., Afonso, A. S., Mattoso, L. H. C., Orts, W. J., \& Medeiros, E. S. (2011). Nano and submicrometric fibers of Poly(D, L-Lactide) obtained by solution blow spinning: Process and solution variables. Journal of Applied Polymer Science, 122, 3396-3405. http://dx.doi.org/10.1002/app.34410

Oliveira, J. E., Grassi, V., Scagion, V. P., Mattoso, L. H. C., Glenn, G. M., \& Medeiros, E. S. (2013). Sensor array for water analysis based on interdigitated electrodes modified with fiber films of poly(lactic acid)/multiwalled carbon nanotubes. IEEE Sensors Journal, 13(2), 759-766. http://dx.doi.org/10.1109/JSEN.2012. 2226715

Oliveira, J. E., Moraes, E. A., Marconcini, J. M., Mattoso, L. H. C., Glenn, G. M., \& Medeiros, E. S. (2013). Properties of poly(lactic acid) and poly(ethylene oxide) solvent polymer mixtures and nanofibers made by solution blow spinning. Journal of Applied Polymer Science, 129(6), 3672-3681. http://dx.doi.org/10. 1002/app.3906

Pérez, S., \& Samain, D. (2010). Structure and engineering of celluloses. Advances in Carbohydrate Chemistry and Biochemistry, 64, 25-116. http://dx.doi.org/10. 1016/S0065-2318(10)64003-6

Pa, M., \& Ahola, S. (2007). Enzymatic hydrolysis combined with mechanical shearing and high-Pressure homogenization for nanoscale cellulose fibrils and strong gels. Macromolecules, 1934-1941.

Parize, D. D. S., Foschini, M. M., de Oliveira, J. E., Klamczynski, A. P., Glenn, G. M., Marconcini, J. M., \& Mattoso, L. H. C. (2016). Solution blow spinning: Parameters optimization and effects on the properties of nanofibers from poly(lactic acid)/dimethyl carbonate solutions. Journal of Materials Science, 51(9), 1-12. http://dx.doi.org/10.1007/s10853-016-9778-x 
Parize, D. D. S., Oliveira, J. E., Foschini, M. M., Marconcini, J. M., \& Mattoso, L. H. C. (2016). Poly(lactic acid) fibers obtained by solution blow spinning: Effect of a greener solvent on the fiber diameter. Journal of Applied Polymer Science, 43379, 1-10. http://dx.doi.org/10.1002/app.43379

Pirani, S., Abushammala, H. M. N., \& Hashaikeh, R. (2013). Preparation and characterization of electrospun PLA/nanocrystalline cellulose-based composites. Journal of Applied Polymer Science, 130(5), 3345-3354. http://dx. doi.org/10.1002/app.39576

Prins, M. J., Ptasinski, K. J., \& Janssen, F. J. J. G. (2006). Torrefaction of wood. Part 1. Weight loss kinetics. Journal of Analytical and Applied Pyrolysis, 77, 28-34. http://dx.doi.org/10.1016/j.jaap.2006.01.002

Raquez, J. M., Murena, Y., Goffin, A. L., Habibi, Y., Ruelle, B., DeBuyl, F., \& Dubois, P. (2012). Surface-modification of cellulose nanowhiskers and their use as nanoreinforcers into polylactide: A sustainably-integrated approach. Composites Science and Technology, 72(5), 544-549. http://dx.doi.org/10.1016/j. compscitech.2011.11.017

Raquez, J.-M., Habibi, Y., Murariu, M., \& Dubois, P. (2013). Polylactide (PLA)-based nanocomposites. Progress in Polymer Science, 38(10-11), 1504-1542. http://dx. doi.org/10.1016/j.progpolymsci.2013.05.014

Roman, M., \& Winter, W. T. (2004). Effect of sulfate groups from sulfuric acid hydrolysis on the thermal degradation behavior of bacterial cellulose. Biomacromolecules, 5(5), 1671-1677. http://dx.doi.org/10.1021/bm034519

Rosa, M. F., Medeiros, E. S., Malmonge, J. A., Gregorski, K. S., Wood, D. F., Mattoso, L. H. C., .. . \& Imam, S. H. (2010). Cellulose nanowhiskers from coconut husk fibers: Effect of preparation conditions on their thermal and morphological behavior. Carbohydrate Polymers, 81(1), 83-92. http://dx.doi.org/10.1016/j. carbpol.2010.01.059

Satyamurthy, P., Jain, P., Balasubramanya, R. H., \& Vigneshwaran, N. (2011). Preparation and characterization of cellulose nanowhiskers from cotton fibres by controlled microbial hydrolysis. Carbohydrate Polymers, 83(1), 122-129. http://dx.doi.org/10.1016/j.carbpol.2010.07.029

Silverstein, R. M., \& Webster, F. X. (2000). Identificação espectrométrica de compostos orgânicos. Rio de Janeiro: LTC.

Siqueira, G., Bras, J., \& Dufresne, A. (2009). Cellulose whiskers versus microfibrils: Influence of the nature of the nanoparticle and its surface functionalization on the thermal and mechanical properties of nanocomposites. Biomacromolecules, 10(2), 425-432. http://dx.doi.org/10.1021/bm801193d

Sofla, M. R. K., Brown, R. J., Tsuzuki, T., \& Rainey, T. J. (2016). A comparison of cellulose nanocrystals and cellulose nanofibres extracted from bagasse using acid and ball milling methods. Advances in Natural Sciences: Nanoscience and Nanotechnology, 7, 35004. http://dx.doi.org/10.1088/2043-6262/7/3/035004
Stape, J. L., Binkley, D., Ryan, M. G., Fonseca, S., Loos, R. A., Takahashi, E. N., ... \& \& Azevedo, M. R. (2010). The Brazil Eucalyptus Potential Productivity Project: Influence of water, nutrients and stand uniformity on wood production. Forest Ecology and Management, 259(9), 1684-1694. http://dx.doi.org/10.1016/j. foreco.2010.01.012

Sun, Y. C., Xu, J. K., Xu, F., \& Sun, R. C. (2013). Structural comparison and enhanced enzymatic hydrolysis of eucalyptus cellulose via pretreatment with different ionic liquids and catalysts. Process Biochemistry, 48(5-6), 844-852. http://dx. doi.org/10.1016/j.procbio.2013.03.023

Teixeira, E. M., Corrêa, A. C., Manzoli, A., Leite, F. L., Oliveira, C. R., \& Mattoso, L. H. C. (2010). Cellulose nanofibers from white and naturally colored cotton fibers. Cellulose, 17(3), 595-606. http://dx.doi.org/10.1007/s10570-010-9403-0

Teixeira, E. M., Bondancia, T. J., Teodoro, K. B. R., Corrêa, A. C., Marconcini, J. M., \& Mattoso, L. H. C. (2011). Sugarcane bagasse whiskers: Extraction and characterizations. Industrial Crops and Products, 33(1), 63-66. http://dx.doi.org/ 10.1016/j.indcrop.2010.08.009

Teodoro, K. B. R., Teixeira, E. M., Corrêa, A. C., Campos, A., de Marconcini, J. M., \& Mattoso, L. H. C. (2011). Whiskers de fibra de sisal obtidos sob diferentes condições de hidrólise ácida: Efeito do tempo e da temperatura de extração. Polímeros, 21(4), 280-285. http://dx.doi.org/10.1590/S010414282011005000048

Teodoro, K. B. R., Campos, A., Corrêa, A. C., Teixeira, E. M., Marconcini, J. M., \& Mattoso, L. H. C. (2016). Surface functionalization of cellulose whiskers for nonpolar composites applications (4th ed.). Handbook of composites from renewable materials (Vol. 8) Wiley., p. 400.

Tian, C., Yi, J., Wu, Y., Wu, Q., Qing, Y., \& Wang, L. (2016). Preparation of highly charged cellulose nanofibrils using high-pressure homogenization coupled with strong acid hydrolysis pretreatments. Carbohydrate Polymers, 136, 485-492. http://dx.doi.org/10.1016/j.carbpol.2015.09.055

Tonoli, G. H. D., Teixeira, E. M., Corrêa, A. C., Marconcini, J. M., Caixeta, L. A., Pereira-Da-Silva, M. A., \& Mattoso, L. H. C. (2012). Cellulose micro/nanofibres from Eucalyptus kraft pulp: Preparation and properties. Carbohydrate Polymers 89(1), 80-88. http://dx.doi.org/10.1016/j.carbpol.2012.02.052

Tutak, W., Sarkar, S., Lin-Gibson, S., Farooque, T. M., Jyotsnendu, G., Wang, D., . . \& \& Simon, C. G. (2013). The support of bone marrow stromal cell differentiation by airbrushed nanofiber scaffolds. Biomaterials, 34(10), 2389-2398. http://dx.doi. org/10.1016/j.biomaterials.2012.12.020

Yu, J. H., Fridrikh, S. V., \& Rutledge, G. C. (2006). The role of elasticity in the formation of electrospun fibers. Polymer, 47(13), 4789-4797. http://dx.doi.org/ 10.1016/j.polymer.2006.04.050 